\title{
Rules and tools: The impact of policy and consensus statements on sternal infection
}

\author{
Leora B. Balsam, MD, ${ }^{\mathrm{a}}$ and Abe DeAnda, $\mathrm{Jr}, \mathrm{MD}^{\mathrm{b}}$
}

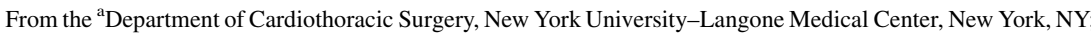
and the ${ }^{\mathrm{b}}$ Division of Cardiothoracic Surgery, University of Texas Medical Branch-Galveston, Galveston, Tex. Disclosures: Authors have nothing to disclose with regard to commercial support.

Received for publication Jan 28, 2016; accepted for publication Jan 28, 2016; available ahead of print March 5 , 2016.

Address for reprints: Leora B. Balsam, MD, Department of Cardiothoracic Surgery, NYU-Langone Medical Center, 530 First Ave, Suite 9V, New York, NY 10016 (E-mail: leora.balsam@nyumc.org).

J Thorac Cardiovasc Surg 2016;152:973-4

$0022-5223 / \$ 36.00$

Copyright (c) 2016 by The American Association for Thoracic Surgery

http://dx.doi.org/10.1016/j.jtcvs.2016.01.041
}

Quality improvement and optimization of outcomes are the mainstay of every cardiothoracic surgery program. The need for well thought-out, evidence-based processes and protocols remains critical. In this issue of the Journal, Lazar and colleagues ${ }^{1}$ have published The American Association for Thoracic Surgery expert consensus review for the prevention and management of sternal wound infections. Postoperative sternal wound infection has garnered recent attention because of public reporting and the impact on reimbursement. One of the consequences of the US Deficit Reduction Act of 2005 was the development of a policy by the Centers for Medicare and Medicaid Services regarding nonreimbursement for the treatment of certain hospital-acquired conditions. Included in this policy is deep sternal wound infection after coronary artery bypass grafting. These regulatory changes have important implications for our practices, and like the public, hospitals are paying attention.

Prevention of infection after cardiac surgery is not a new topic. There is a large body of literature through which risk factors and preventative measures have been identified. The expert consensus review that Lazar and colleagues ${ }^{1}$ present outlines processes for modifying patient-specific risk factors; in addition, they review general practice guidelines for prevention of sternal wound infection. A number of class I recommendations are provided, some with enough supporting material to be considered at a level of evidence of A or B. Other recommendations reflect common use and practice and may appropriately change down the road. The bottom line, however, is that a Bayesian approach (either formal or informal) points to the fact that some patients are more at risk than others, and whether such practices should be applied to all patients is food for thought. For example, Lazar and colleagues ${ }^{1}$ propose that figure-of-eight closure may be preferable for high-risk patients, but it is unclear whether this technique should be universally adopted for all patients. In a review by Alhalawani and Towler ${ }^{2}$ comparing as many as 8 types of

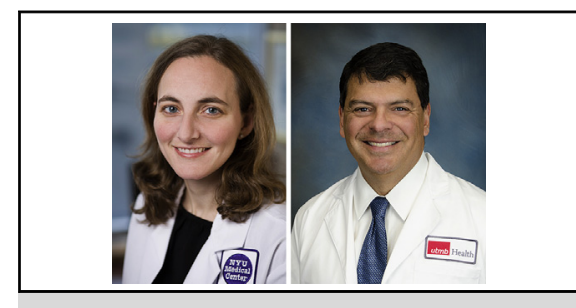

Leora B. Balsam, MD, and Abe DeAnda, Jr, MD

Central Message

Expert consensus review for the prevention and management of sternal wound infections form the foundation on which center-specific directives should be built.

See Article page 962.

closure, they remark that "it is clear that there is no ideal device/material currently available or under test, that can address all the concerns that arise from sternal closure." They saw merit in single-wire closure as well as figure-of-eight closure, depending on the clinical scenario.

It is important to recognize that although deep sternal wound infection after coronary artery bypass grafting consumes resources, significant resources are also needed to avoid it. Prevention of surgical site infection is not the job of the surgeon alone; a multidisciplinary team is involved, and commitment from hospital leadership is paramount. Many hospitals employ an epidemiologist to oversee issues related to infection control, including avoidance of hospital-acquired infections. There are many moving pieces in this puzzle, including patient-specific risk factors, institutional practices, and site-specific issues related to work flow, topography, and resources. In a recent editorial on the risk of sternal infection with arterial grafting, Kurlansky ${ }^{3}$ described these as patient- versus center-level factors. Center-level factors are outside the scope of these consensus statements, and as such the consensus statements form a foundation on which each center must add additional layers of site-specific directives. One recent example at one of our centers involved establishing a work flow for the administration of vancomycin. Unlike cephalosporins, which can be given rapidly, vancomycin is administered as a slow infusion to avoid hemodynamic derangement and red man syndrome. A system had to be established to ensure that the infusion was completed before skin incision to achieve adequate 
tissue levels, which might impact the work flow because this infusion would most likely have to be started before bringing the patient into the room.

Perhaps what is most impressive in the current era of cardiac surgery is that across the board, centers have managed to reduce the incidence of deep sternal wound infection to the low single digits, and sometimes even below $1 \%$. With such a low incidence, research comparing the efficacies of various therapies for prevention (or treatment) of sternal wound infection is difficult to conduct. That said, a search of the term "sternal wound infection" on PubMed retrieved 610 articles published between 2010 and 2016; so whether it is glycemic control, topical antibiotics, skin antisepsis practices, or the role of negative pressure wound therapy for prevention and treatment of sternal infections, someone seems to be trying to study it. Lazar and colleagues $^{1}$ do their best to synthesize this research into the expert consensus review.

The expert consensus review does not address the process for managing upticks in sternal wound infection, should they occur, or how to balance the yin and the yang of patient-level and center-level factors. Lazar and colleagues previously reported a $0 \%$ incidence of sternal infection in 1075 consecutive patients undergoing cardiac surgery with a strategy of tight glycemic control, topical vancomycin to the sternal edges, and perioperative antibiotics. ${ }^{4}$ And while we all strive to be perfect, tools are needed to deal with the imperfections that arise in reality, however rare they may be. Quality improvement projects or root cause analyses have been described to deal with these breakout occurrences, and all require a broad multidisciplinary team. Important members may include not only the clinicians but also staff from bioengineering, environmental services, sterilization services, and pharmacy, to name only a few. It is obvious that certain center-level factors will not be addressed in a consensus statement, and as such each institution must develop its own platform for quality assurance and define systems for performance improvement.

\section{References}

1. Lazar HL, Vander Salm T, Engelman R, Orgill D, Gordon S. AATS consensus guidelines for the prevention and management of sternal wound infections. J Thorac Cardiovasc Surg. 2016;152:962-72.

2. Alhalawani AM, Towler MR. A review of sternal closure techniques. J Biomater Appl. 2013;28:483-97.

3. Kurlansky P. Arterial grafting and the risk of sternal infection: how we can learn from our experience. J Thorac Cardiovasc Surg. 2014;148:1896-8.

4. Lazar HL, Ketchedijan A, Haime M, Karlson K, Cabral H. Topical vancomycin in combination with perioperative antibiotics and tight glycemic control helps to eliminate sternal wound infection. J Thorac Cardiovasc Surg. 2014;148:1035-8; $1038-40$. 